\title{
Uma etnografia em ambiente carcerário e sobre o crime organizado
}

Resenha: BIONDI, Karina. Junto e Misturado: uma etnografia do PCC (ebook). 1. ed. São Paulo: Editora Terceiro Nome, 2014 [2010].

Wesley Lima dos Santos ${ }^{1}$

A autora da obra "Junto e Misturado - Uma etnografia do PCC", Karina Biondi, possui graduação em Ciências Sociais pela Universidade de São Paulo (2005), mestrado (2009) e doutorado (2014) em Antropologia Social na Universidade Federal de São Carlos. Fez pós-doutorado na Universidade Estadual de Campinas (2016) e na Universidade Federal de São Carlos (2017). Atualmente, é professora adjunta na Universidade Estadual do Maranhão. Além da obra objeto dessa resenha, é autora de livros como Proibido roubar na quebrada e Território, hierarquia e lei no PCC (Melhor Livro do Ano de Ciências Sociais 2019, da LASA - Latin American Studies Association).

"Junto e Misturado" é uma obra antropológica, produzida com o intuito de ser acessível para pessoas de qualquer formação. Trata-se da primeira etnografia sobre o Primeiro Comando da Capital (PCC). O ambiente carcerário é o cenário desse estudo repleto de experiências, conflitos e controvérsias. O registro acaba por verter na antropologia política, ao analisar a experiência política da relação entre o PCC e o sistema carcerário paulista. Logo no início, a autora chama atenção para a dificuldade em traçar um texto final dentro da cronologia temporal e conceitual.

\footnotetext{
${ }^{1}$ Wesley Lima dos Santos, Mestrando no PPGCS/EFLCH - UNIFESP, wlsantos@unifesp.br.
} 
A introdução por ser também um pequeno guia de fatos comuns da experiência de campo, incluindo o caderno de campo e como as experiências vividas são selecionadas, escritas, já as tratando em algum grau de relevância frente aos objetivos. Os primeiros relatos relacionam-se ao ambiente externo dos Centros de Detenção Provisória (CDP). A rotina das visitas é detalhada para explicar as práticas comuns nos chamados dias de visita. Nesse momento já se nota uma certa tensão e disciplina para organizar as filas de ingresso na unidade carcerária. As controvérsias do termo disciplina ${ }^{2}$ já começam a surgir mesmo entre as visitas, como nota-se na passagem em que Biondi descreve o relato de uma mulher condenando as que não respeitam à disciplina, dizendo que, na verdade, as mulheres seriam espelho dos homens que visitam. Ou seja, se um fosse "sem futuro" o outro também seria

Alguns códigos nativos podem ser detectados na descrição das relações entre as esposas. Por exemplo, o nível de caminhada ${ }^{3}$ de cada esposa se dá na ordem de grandeza em que ela se dedica ao esposo e esse é um código particular que acaba por demonstrar as posições das companheiras frente aos detentos. A questão de gênero aparece em uma visão micro da obra, especialmente ao falar do respeito dos presos com visitas de colegas e na ideia de posse implícita nesse respeito.

Adentrando na disciplina do comando é possível pensar os dilemas enfrentados para desenvolver uma pesquisa com essa envergadura. O problema ético presente em outros estudos etnográficos foi pensado nesse de modo a considerar a relação aproximada com o crime e os desdobramentos judiciais desse vínculo.

Vargas (2006) em referência mobilizada pela autora trata que "recusar o consenso moral não significa fazer apologia [ao crime], mas alimentar a controvérsia em busca de alternativas consequentes que levem em conta a afirmação eticamente sustentada da pluralidade imanente dos modos de existência”. Posto isso, para realizar esse estudo foi preciso ter autorização de um irmão ${ }^{4}$, ainda que não fosse autorização geral ou de algum possível líder hierárquico, essa autorização geraria consequências ao irmão em caso de qualquer problema.

\footnotetext{
2 Os códigos/gírias utilizadas pelos agentes são elencados no dicionário da obra. Disciplina ou disciplina do comando são as condutas recomendadas aos participantes do PCC.

3 Caminhada: (1) Histórico (“Qual a sua caminhada?”). (2) Série de procedimentos a serem cumpridos ("Me ensinou a caminhada").

4 Irmão: Membro "batizado" no PCC.
} 
Karina Biondi trata o aval5 do comando para a pesquisa como revelador, justamente por romper com o senso comum envolto no conceito de "organização criminosa" como altamente hierarquizada. Do ponto de vista político, todos os irmãos falam em nome do comando e essa percepção fez com que os pontos de partida no campo fossem se delineando.

O livro nos faz pensar que quando se fala em PCC e em seus agentes, a facção pode estar "presente inclusive onde está ausente", conforme destacado em alguns pontos do registro. Isso é identificável em referências feitas às visitas e a pessoas direta ou indiretamente ligadas às práticas do comando.

Nas ressalvas metodológicas dirigidas à Latour é possível notar a intenção de capturar a percepção do nativo, pois o não enquadramento conceitual, ou seja, o afastamento de conceitos polissêmicos como cultura e sociedade não se mostrou eficaz para entender o ponto de vista dos indivíduos imbricados nessas realidades.

O PCC surge como uma força de resistência às condições carcerárias a que estavam submetidos os detentos. A megarrebelião de 2001, que aconteceu simultaneamente em diferentes presídios do estado de São Paulo, é a primeira grande manifestação do PCC com autoria assumida e desde então vários eventos descritos demonstram a influência política da facção, culminando nos eventos de 2006, quando houve uma série de ataques programados às forças de segurança e mesmo a algumas instituições estatais. Versões de integrantes consultados apontam o surgimento em meados de 1993. Presos antigos tratam o período pós advento do partido 6 como uma melhora importante na disciplina prisional que passou a se ter tanto na relação entre presos, quando no sistema $a^{7}$ de modo geral. Ainda nessa chave, por muito tempo o alto escalão da segurança pública do estado de São Paulo tratou a possível existência da facção como ficção.

Os ataques de 2006 despertaram o interesse da academia em entender esses fenômenos. Esse período, conforme demonstrado no capítulo “O PCC”, acaba por

\footnotetext{
5 Aval: Autorização.

6 Partido: O mesmo que PCC.

${ }^{7}$ Sistema: Entendimento polissêmico, sendo: (1) Presos. (2) Sistema penitenciário (instituições privativas de liberdade e seus funcionários). (3) Sistema capitalista. (4) Poder Público
} 
impulsionar pesquisadores das universidades a se debruçar através de diversas perspectivas, com o intuito de capturar o funcionamento e as estruturas da facção.

Como forma de diagnóstico de unidades de grandeza, na época da produção estudo de Karina Biondi a população carcerária no Rio de Janeiro, amplamente presente nos noticiários era quase 6 vezes menor em relação à população carcerária do estado de São Paulo ${ }^{8}$. Além disso, em alguns casos, como nos CDPs as funções não cumpridas de modo devido. Nos Centros de Detenção Provisória, conforme apontado, não são raros os casos de detentos passando períodos equivalentes ao que cumpririam de pena, sem ao mesmo serem julgados.

No aspecto de territorialidade, a organização criminosa passou a "tomar" para si diversas cadeias dentro e fora do estado, em alguns casos aderindo aos confrontos. Do ponto de vista prático, não há diálogo entre integrantes de facções rivais, logo encaminhar um detento de uma facção para um presídio dominado por outra é considerado como uma sentença de morte.

Há uma certa ordem adotada nas chamadas "prisões do comando". Os detentos recém-chegados passam por triagem composta por perguntas com a intenção entender seu proceder $^{9}$ e o tipo de caminhada. Não existem dados parametrizados que informem o número de membros batizados ${ }^{10}$ do PCC, a autora através de critérios de observação apontou para um cálculo da ordem de um batizado a cada 100 detentos. Por essa razão, os critérios para o batismo costumam ser tão rígidos entre os membros, pois assim como no caso aval, um integrante batizado passa a ter parte de suas ações vinculadas à responsabilidade de seu padrinho ${ }^{11}$ no crime.

Esse é um ponto importante, por colocar em evidência o momento de transição dos ideais de "paz, justiça e liberdade", para a inclusão do fundamento da "igualdade" no comando. Nessa transição se pode pensar em diversas outras controvérsias acerca da estrutura de tomada de decisão do PCC. Trata-se de um ponto de transição importante por colocar em evidência a percepção da autora frente ao

\footnotetext{
${ }^{8}$ De acordo com as informações constantes no livro, a população carcerária de SP em dezembro de 2007 era de 153.056 detentos, enquanto a população carcerária do RJ era de 26.523 detentos.

${ }^{9}$ Proceder: Comportamento esperado de um prisioneiro, por meio do qual ele é avaliado pelos outros presos.

10 Batizado: indivíduo que passou de "primo" para "irmão".

11 Padrinho: "Irmão" que propôs o "batismo" de outro "irmão" e que carrega a responsabilidade por trazer este novo membro ao PCC.
} 
grupo estudado. Serve como forma de desmistificar o estereótipo criado no senso comum do grupo altamente hierarquizado e com posições de comando bem estabelecidas. Partindo dessa leitura para avaliar a emergência do Primeiro Comando da Capital, em conjunto com uma reflexão que comporte o sistema prisional brasileiro.

A inserção do ideal de igualdade passa a tornar ainda mais complexa a relação de $v o z^{12}$ e disciplina. Em algumas passagens esse confronto entre igualdade, humildade e a necessidade da palavra de autoridade é demonstrado de forma evidente. Retomando o relato do ponto de vista dos detentos, demonstrou-se uma impressão de pacificação do ambiente carcerário descrito nos anos 90. A superação do problema do crack e a não tolerância aos chamados malandrões ${ }^{13}$ são conquistas citadas por irmãos e primos $^{14}$ durante essas conversas.

Assim também esse controle é exercido através das posições de ordem dentro e fora do ambiente carcerário. Os faxinas ${ }^{15}$, pilotos $^{16}$ e as torres ${ }^{17}$, são alguns dos papéis estruturantes do comando, tanto para manter o controle, quanto para receber os chamados salves vindos do mundão. Todos esses códigos e categorias eram de conhecimentos dos presos, no entanto a pesquisa aparentemente não explorou a leitura dos funcionários acerca dessas funções.

O respeito interno entre membros acaba por crescer de acordo com a capacidade de um irmão lidar com os problemas no crime. O lema de igualdade acaba por gerar ainda mais controvérsias se olharmos com uma lupa linhas históricas descritas pelo livro. $\mathrm{Na}$ resolução de conflitos entre membros essa capacidade de negociação e argumentação é colocada em prova e diferente do crava o estereótipo, entre os entrevistados é unânime a ideia de que o respeito se dá por quem tem mais capacidade de negociação, ou seja, de não tomar uma postura violenta desde o início.

\footnotetext{
12 Voz: Posição política que existia em cada cela (voz do barraco), em cada pavilhão e em cada cadeia.

13 Malandrão: Preso típico da época que antecedeu a existência do PCC, caracterizada pela exploração financeira e sexual de outros presos.

14 Primo: Presos que residem no "convívio" de cadeias comandadas pelo PCC, mas que não são seus membros "batizados".

${ }^{15}$ Faxina: (1) Cela onde moram presos responsáveis por funções políticas e administrativas no interior de um pavilhão. (2) Nome dado aos moradores da cela "faxina".

16 Piloto: Posição política exercida por presos, responsável pelo bloco.

17 Torre: Posição política existente no PCC, responsável pelos “salves” que orientam as ações dos presos.
} 
Com a mobilização de referências da literatura política, nota-se que a obra considera a inexistência de obrigações e de estrutura hierárquica como um ponto fundamental da coesão do PCC. Latour (2005) e Viveiros de Castro (2002) são citados na obra em aceno para uma abordagem menos dicotômica em relação às abordagens voltadas para a "sociologia do social" (preterida) e aproximando-se da "sociologia das associações" (adotada).

A supressão das posições de autoridade foi apreendida no decorrer do estudo, tanto pela alteração do lema, quanto para as práticas do dia-a-dia do cárcere. Na linha disciplinar do comando, historicamente homossexuais não são aceitos e ainda que isso tenha mudado com o advento do lema de igualdade, o regime parece ser apenas de tolerância, mas sem a participação na tomada de decisões.

Ao longo do terceiro capítulo passa a se criticar o enquadramento de categorias como "organização criminosa" e "crime organizado". Inclusive reitera-se as fortalezas do método etnográfico para considerar em patamar equitativo os saberes acadêmicos e aqueles apreendidos do nativo. Se afastando, portanto, de leituras jurídicas ortodoxas. Essa crítica demonstra o poder de coesão do PCC ao pensar a horizontalidade do "estar misturado", ou seja, correr lado a lado's.

Por todas essas complexidades, a organização perdura em ideais, adeptos e cresce territorialmente desde sua formação. Talvez essa possa ter sido uma dificuldade denotada nas camadas mais profundas da pesquisa, seguir os agentes (em especial as visitas e os funcionários) em práticas não necessariamente vinculadas com o comando ou com o sistema penitenciário.

Um ponto que pode gerar impressões dissonantes no leitor é se de fato a perspectiva pacificadora do comando sobrepõe a violência ainda empregada em suas práticas. Seja contra o Estado, seja contra quem não faz parte do comando dentro da ideia de "quem não corre com o Comando corre contra, é oposição", seja contra facções rivais.

Em suma, a pesquisa é repleta de fortalezas na metodologia e na forma acessível como foi transcrita. A autora colabora para a discussão da violência e direitos humanos nas prisões brasileiras e amplia essa reflexão ao pensar a origem e a estrutura

\footnotetext{
${ }^{18}$ Lado a lado: Qualidade da relação entre duas ou mais pessoas, na qual existe uma cooperação desprovida de hierarquia.
} 
do Primeiro Comando da Capital. Contribui também para a leitura de organização criminosa e a aderência desse conceito ao modelo estrutural visto nessa facção. Como escopo demonstra cuidado nos detalhes, tornando a obra atrativa ao incluir um dicionário detalhado e o croqui de um dos espaços estudados.

\section{Referências}

LATOUR, Bruno. Reagregando o social Uma introdução à teoria do Ator-Rede, Salvador: Edufba, 2012 [2005]; Bauru, São Paulo: Edusc, 2012.

VARGAS, Eduardo Viana. 2006. Uso de drogas: a alteração como evento. Revista de
Antropologia USP, v. 49, n 2, São Paulo. p. 581-623.

VIVEIROS DE CASTRO, Eduardo. 2002. O Nativo Relativo. Mana, vol. 8, no 1. Rio de Janeiro: UFRJ. p. 113-148. 